\title{
Beliefs related to insulin use in people with Type 2 Diabetes Mellitus
}

\author{
Crenças relacionadas ao uso de insulina em pessoas com Diabetes Mellitus tipo 2 \\ Creencias relacionadas con el uso de insulina en personas con Diabetes Mellitus tipo 2
}

Bernadete de Lourdes André Gouveia' ORCID: 0000-0001-8133-6048

Mailson Marques de Sousa' ORCID: 0000-0002-8099-4310

Taciana da Costa Farias de Almeida' ORCID: 0000-0002-9390-9656

Vinicius André Gouveia de Sousa' ORCID: 0000-0003-1965-6811

Simone Helena dos Santos Oliveira' ORCID: 0000-0002-9556-1403

'Universidade Federal da Paraíba. João Pessoa, Paraíba, Brazil.

How to cite this article:

Gouveia BLA, Sousa MM, Almeida TCF, Sousa VAG, Oliveira SHS. Beliefs related to insulin use in people with Type 2 Diabetes Mellitus. Rev Bras Enferm. 2020;73(3):e20190029. doi: http://dx.doi.org/10.1590/0034-7167-2019-0029

Corresponding author: Bernadete de Lourdes André Gouveia E-mail: bernagouveia46@gmail.com

EDITOR IN CHIEF: Antonio José de Almeida Filho ASSOCIATE EDITOR: Hugo Fernandes

Submission: 02-11-2019

Approval: 05-10-2019

\begin{abstract}
Objectives: to identify the beliefs of people with Type 2 Diabetes Mellitus related to insulin use. Methods: a descriptive, cross-sectional, quantitative-qualitative study based on Theory of Planned Behavior and performed with 32 participants using insulin. The data were analyzed and grouped into categories by beliefs similarity, counted from the frequencies. Results: 118 behavioral, 60 normative and 97 control beliefs were issued. Among the behavioral beliefs, there was an advantage in keeping the diabetes under control and disadvantage, the pain of being pierced by the application of insulin. Regulations highlighted the children as referents who support the treatment. In control beliefs, it was observed that the application of insulin appears as easiness and difficulty to the treatment. Conclusions: the study will support the construction of a psychometric scale to measure the determinants of insulin use, revealing particularities for the structuring of educational interventions that contribute to adherence of the treatment verified in adequate glycemic control.

Descriptors: Beliefs; Type 2 Diabetes; Insulin Therapy; Behavior in Health; Nursing.
\end{abstract}

\section{RESUMO}

Objetivos: identificar as crenças de pessoas com Diabetes Mellitus tipo 2, relacionadas ao uso de insulina. Métodos: estudo descritivo, transversal e quanti-qualitativo, fundamentado na Theory of Planned Behavior e realizado com 32 participantes em uso de insulina. Os dados foram analisados e agrupados em categorias pela similitude das crenças, contabilizados a partir das frequências. Resultados: foram emitidas 118 crenças comportamentais, 60 normativas e 97 de controle. Entre as crenças comportamentais, destacou-se vantagem em manter o diabetes controlado e desvantagem, dor da furada pela aplicação de insulina. As normativas destacaram os filhos como referentes que apoiam o tratamento. Nas crenças de controle, observou-se que a aplicação da insulina aparece como facilidade e dificuldade ao tratamento. Conclusões: o estudo subsidiará a construção de escala psicométrica para mensurar os fatores determinantes do uso da insulina, desvendando particularidades para estruturação de intervenções educativas que contribuam com adesão do tratamento verificado no controle glicêmico adequado.

Descritores: Crenças; Diabetes Tipo 2; Insulinoterapia; Comportamento em Saúde; Enfermagem.

\section{RESUMEN}

Objetivos: identificar las creencias de personas con Diabetes Mellitus tipo 2, relacionadas con el uso de insulina. Métodos: el estudio descriptivo, transversal y cuantitativo, fundamentado en la Theory of Planned Behavior y realizado con 32 participantes en uso de insulina. Los datos fueron analizados y agrupados en categorías por la similitud de las creencias, contabilizados a partir de las frecuencias. Resultados: se emitieron 118 creencias comportamentales, 60 normativas y 97 de control. Entre las creencias comportamentales, se destacó la ventaja en mantener la diabetes controlada y desventaja, dolor de la perforación por la aplicación de insulina. Las normativas destacaron a los hijos como referentes que apoyan el tratamiento. En las creencias de control, se observó que la aplicación de la insulina aparece como facilidad y dificultad al tratamiento. Conclusiones: el estudio subsidiará la construcción de escala psicométrica para medir los factores determinantes del uso de la insulina, desvelando particularidades para la estructuración de intervenciones educativas que contribuyan con adhesión del tratamiento verificado en el control glucémico adecuado.

Descriptores: Creencias; Diabetes Tipo 2; Insulina; Comportamiento en Salud; Enfermería. 


\section{INTRODUCTION}

Diabetes Mellitus (DM) stands out in the scope of chronic diseases of high incidence and prevalence in the world setting. It is directly related to the phenomenon of aging populations, habits and lifestyle harmful to health, such as physical inactivity and inadequate food consumption, which contribute to overweight and obesity ${ }^{(1-2)}$.

Worldwide, the DM is on the rise and projections indicate that by the year 2035, about 592 million people will develop the disease, being characterized in a difficult to control epidemic ${ }^{(3)}$. Regarding the therapeutic approach (oral antidiabetic and insulin therapy) and non-pharmacological (physical activity and healthy diet), these are essential for health maintenance and minimization of acute and chronic complications ${ }^{(4)}$.

Evidence in the literature indicates low adherence to oral treatment among patients with Type 2 Diabetes Mellitus (2DM) ${ }^{(5-8)}$. Adverse effects, complex therapeutic regimen, difficulties in understanding the therapeutic prescription, forgetfulness, financial resources for medication acquisition, daily routine, fragility in the outpatient follow-up and prolonged diagnosis are factors described for non-adherence to the Oral Antidiabetic regimen (OAD) $)^{(5,8-11)}$. As a result of low oral therapeutic adherence, it is necessary to introduce insulin therapy as the last pharmacological resource to achieve clinical stability of the disease, due to the lack of control of glycemic levels. Another study, whose objective was to identify the factors associated with glycemic control in people with 2DM, pointed out weaknesses in the injectable therapeutic regimen, so that people with 2DM in insulin use had a significantly higher probability of presenting inadequacy in glycemic control(9).

Thus, it is necessary to develop studies that seek to optimize adherence to the therapy indicated for each case. Moreover, identification of motivational or determinant factors of the behavior that one wishes to achieve is of substantial importance for the planning of health interventions. In the meantime, beliefs, understood as antecedents of behavior, become the interest of research whose goal resides in the behavioral influence.

As a theoretical and methodological framework that involves beliefs as one of its constructs, Theory of Planned Behavior (TPB) from social psychology has been used in the study of phenomena in the context of health to analyze beliefs, predict and explain the motivation of the individual in perform specific behaviors ${ }^{(12)}$. According to the TPB, intention is considered to be an immediate antecedent of behavior, formed by three constructs: attitude (formed by behavioral beliefs, which relates to the subject's favorability as to whether or not to behave and to assess positive or negative consequences for the conduct of the conduct in question); subjective norm (it refers to social influence, that is, the perceived social pressure constituted by normative beliefs that reflect in the individual's perception of the opinions of his / her social referents about the performance or not of the behavior, and in the individual motivation to agree with the social referents) and perceived behavioral control (formed by control beliefs, consists of the individual's perceptions regarding the ability to perform behavior or not, as well as the presence of factors that may facilitate or hinder their performance) ${ }^{(12)}$.

In the literature, it is possible to identify that the applicability of TPB in studies to raise the beliefs of patients with 2DM in OAD use in the international $\left.\right|^{(5,11,13)}$ and Brazilian setting ${ }^{(8)}$. However, in the context of insulin therapy, studies are non-existent. Thus, it is relevant to unveil the beliefs inherent in insulin use therapy in people with 2DM.

The importance of research for clinical nursing practice is emphasized, since the results obtained will support the elaboration of psychometric scales of behavioral measure and care technologies to promote health-protective behaviors of people with 2DM. In addition, the findings may clarify the difficulties and difficulties in using insulin, contributing to improve self-care management and quality of life. Therefore, the following guiding question was proposed for the screen study: what are the beliefs of people with 2DM about insulin use?

\section{OBJECTIVES}

To identify the beliefs of people with Type 2 Diabetes Mellitus related to insulin use.

\section{METHODS}

\section{Ethical aspects}

The study was approved by the Research Ethics Committee (REC) of the Hospital Universitário Lauro Wanderley, with Opinion 2,446,500.

\section{Design, period and place of study}

It is a descriptive, cross-sectional and quantitative-qualitative study, based on TPB. TPB is a theoretical-methodological model that aims to predict and explain human behavior in specific contexts.

According to the theoretical precepts of TPB, to predict behavioral intention from the theoretical constructs (attitude, subjective norm and perceived behavioral control), it becomes necessary to identify the salient modal beliefs about the phenomenon of interest. Beliefs are defined as basic cognitive structures that motivate attitude. They may be altered by various cognitive and motivational processes ${ }^{(14-15)}$. Outgoing beliefs are those available in memory when activated, that is, belief is emitted immediately after questioning, without any cognitive effort.

Also, following the theoretical recommendations, we defined the behavior of interest of the study - to use insulin for DM, according to prescription in the next 30 days, which contemplates the elements of target, action, context and time, according to the assumptions theoreticians adopted.

The study was carried out at the endocrinology outpatient of the Hospital Universitário Lauro Wanderley (HULW), municipality of João Pessoa, Northeast Brazil, with people with 2DM. Data collection took place between December 2017 and January 2018, through an individual interview and in an environment reserved in said outpatient clinic.

\section{Population or sample; inclusion and exclusion criteria}

According to recommendations of the theoretical model, there is no requirement as to the number of participants to survey beliefs about a behavior. However, the number of up to 30 participants is suggested to reach the saturation criterion of the responses issued, when the speeches are repeated and do not add new information ${ }^{(16)}$. Thus, 32 subjects integrated the sample.

The inclusion criteria proposed for the study were: people aged $\geq 18$ years, of both genders, in regular use of insulin therapy and 
cognitive conditions, evaluated for the ability to express birth date, day, month and year. People with insulin-associated OAD and with neurological deficit were excluded as confirmed in medical records.

\section{Study protocol}

Two tool were used to collect data. The first tool was a questionnaire containing sociodemographic and clinical questions to characterize the participants. The second tool was a structured form with six open questions in the format of free responses, in order to elicit the behavioral, normative and control beliefs elaborated, according to the guidelines of the TPB ${ }^{(12)}$.

For the survey of behavioral beliefs, the following questions were elaborated: "In your opinion, what are the advantages of correctly taking the insulin prescribed for diabetes in the next 30 days?", "In your opinion, what are the disadvantages of correctly taking insulin prescribed for diabetes next 30 days?". Obtaining normative beliefs occurred from the following questions: "Which people are important to you, who think you should take the prescribed insulin for diabetes within 30 days?",'Which people are important to you, who think that you should not take the insulin prescribed for diabetes the next 30 days?". Control beliefs were assessed through questions: "In your opinion, what is the easiness to properly take the insulin prescribed for diabetes the next 30 days?","In your opinion, what are the difficulties to properly take the insulin prescribed for diabetes within 30 days?".

\section{Analysis of results and statistics}

The responses were transcribed and grouped by similarity and then transposed to a Microsoft Excel for Windows version 2016 spreadsheet for processing and analysis by means of descriptive statistics, with determination of outgoing modal beliefs.

For the present investigation, the most frequent emissions were considered as salient modal beliefs, that is, those that were mentioned five or more times, with a frequency equal to or greater than $10 \%$, which together were above $75 \%$ in total of the replies issued ${ }^{(16)}$.

\section{RESULTS}

The sample consisted of 32 participants with 2DM and in outpatient follow-up. With regard to sociodemographic characteristics, it was observed that women had a higher participation, 24 (75\%); the mean age was 56.5 years (ranging from 39 to 77 years); 21 $(65.6 \%)$ self-declared themselves non-white; 18 (56.3\%) were from João Pessoa City and 14 (43.7\%) from other municipalities; $20(62.5 \%)$ were married or had a stable union; 14 (43.7\%) were illiterate or had incomplete elementary education and 13 (40.6\%) finished high school; 22 (68.7\%) were inactive and 20 (62.5\%) lived with an average income of up to two minimum wages.

Regarding the clinical characteristics, the mean time of diagnosis was 14.3 years ranging from one to 30 years. The average capillary blood glucose performed on the day of care was $191 \mathrm{mg}$ / dl, ranging from 64 to $440 \mathrm{mg} / \mathrm{dl}$. As for glycated hemoglobin recorded in medical records, the mean was $5.8 \%$ with a minimum of $5.3 \%$ and a maximum of $14.9 \%$.

In the investigation of other diseases associated with 2DM, 22 (68.8\%) had Hypertension, 3 (9.3\%) were overweight; each person (3.1\%) had Lupus, Gastritis, Allergy and Osteoporosis. Nine (28\%) had diabetic complications, such as peripheral neuropathy, four (12.5\%) had retinopathy, two (6.2\%) had nephropathy two and one (3.1\%) had cardiovascular disease. Regarding healthy habits, $23(71.8 \%)$ did not practice physical activity and 22 (68.8\%) had no nutritional monitoring. Smoking and alcoholism were reported by three (15.6\%) of the investigated. Insulin use-associated medications for other comorbidities was reported by 23 (71.8\%). Antihypertensive and diuretic agents were recorded for most of them.

Regarding beliefs analysis, it is observed that among the behavioral ones (advantages and disadvantages in using insulin), the maintenance of the control of the DM as positive belief and pain of the hole in the application of the insulin as negative belief stands out. Categories and frequencies of beliefs are presented in Table 1.

Regarding normative beliefs (positive referents), the participants identified four important social groups that positively influence insulin intake: children, husband/wife, mother and siblings observed in Table 2.

It was possible to identify that of the 32 participants, 22 (68.7\%) reported that there are no important people who disagree with the behavior of taking the insulin prescribed for 2DM control. However, an emission for relative and uncle was observed; two for children, husband, brothers and friends. Considering the criterion of including the beliefs emitted by at least five times and frequency of $10 \%$, it is observed the absence of negative modal referential salient for the execution of the behavior.

Table 3 presents the control beliefs (factors that facilitate or hinder insulin use). It is verified that the ease in the application of insulin, although referenced only by 10 (30.3\%), is a contributing factor for the correct drug use. However, the difficulty in applying the insulin reported by 22 (34.4\%) stands out as a strong barrier to behavior.

Table 1 - Positive and negative behavioral beliefs in taking insulin for 2DM ( $n=32)$, João Pessoa, Paraíba, Brazil, 2018

\begin{tabular}{|c|c|c|c|c|c|}
\hline \multicolumn{6}{|c|}{ BEHAVIORAL BELIEFS } \\
\hline Advantage & $\mathbf{n}$ & $\%$ & Disadvantage & $\mathbf{n}$ & $\%$ \\
\hline Keep DM controlled & 25 & 44.6 & Pain from pierced for insulin application & 32 & 51.6 \\
\hline Getting better and safer & 12 & 21.4 & Adverse effects* & 08 & 13 \\
\hline Rapid effect on disease control and blood glucose & 09 & 16.0 & Application location - belly & 08 & 13 \\
\hline Do not take insulin-associated OAD & 06 & 11.0 & Depend on others for application & 05 & 8.0 \\
\hline Regained weight & 02 & 3.5 & Embarrassment to take away from home & 05 & 8.0 \\
\hline Do not forget to take insulin & 02 & 3.5 & Obligation to take every day & 04 & 6.4 \\
\hline Total & 56 & 100 & & 62 & 100 \\
\hline $\mathrm{OBB}^{* *}$ & 52 & 93 & & 48 & 77.6 \\
\hline
\end{tabular}

Note: *Hypoglycemia, mild bleeding, purplish spots, and application site hardening; **Outgoing behavioral beliefs; DM - Diabetes Mellitus. 
Table 2 - Positive normative beliefs (positive referents) in taking insulin for 2DM (n=32), João Pessoa, Paraíba, Brazil, 2018

\begin{tabular}{|c|c|c|}
\hline \multicolumn{3}{|c|}{ NORMATIVE BELIEFS } \\
\hline Positive Referents & $\mathbf{n}$ & $\%$ \\
\hline Children & 23 & 38.3 \\
\hline Husband/wife & 10 & 16.7 \\
\hline Mom & 08 & 13.3 \\
\hline Siblings & 06 & 10.0 \\
\hline Health professionals (medical and health agent) & 04 & 6.7 \\
\hline God & 03 & 5.0 \\
\hline Own patient & 03 & 5.0 \\
\hline Total & 60 & 100 \\
\hline *PNPB & 47 & 78.3 \\
\hline
\end{tabular}

Note: *Positive normative positive beliefs.

Table 3 - Control beliefs (easiness and difficulties) in taking insulin for 2DM (n=32), João Pessoa, Paraíba, Brazil, 2018

\begin{tabular}{|c|c|c|c|c|c|}
\hline \multicolumn{6}{|c|}{ CONTROL BELIEFS } \\
\hline Easiness & $\mathbf{n}$ & $\%$ & Difficulties & $\mathbf{n}$ & $\%$ \\
\hline Ease of application of insulin & 10 & 30.3 & Difficulty in the application of insulin & 22 & 34.4 \\
\hline Free insulin delivery & 08 & 24.2 & Resistance to accepting insulin & 12 & 18.8 \\
\hline Getting used to the routine of taking insulin & 06 & 18.2 & Purchasing insulin (expensive) & 11 & 17.2 \\
\hline Only take once a day & 05 & 15.1 & Needle Piercing Pain & 09 & 14.0 \\
\hline Idiosyncratic & 03 & 9.1 & Idiosyncratic & 07 & 10.9 \\
\hline Does not give gastritis & 01 & 3.1 & No place to apply when leaving home & 03 & 4.7 \\
\hline Total & 33 & 100 & Total & 64 & 100 \\
\hline${ }^{*} \mathrm{BCPOMB}$ & 29 & 87.7 & ${ }^{*} \mathrm{BCPOMB}$ & 54 & 84.4 \\
\hline
\end{tabular}

Note: *Behavioral control perceived outgoing modalities beliefs.

\section{DISCUSSION}

In the sociodemographic results of the participants' profile, there was evidence of a predominance of females, with a mean age of 56.5 years, similar to studies on adherence to OAD ${ }^{(5,17)}$. Low schooling, marriage or stable union, inactive and income of up to two minimum wages are also characteristics identified in previous studies in the Brazilian setting among people with $2 \mathrm{DM}^{(8,18)}$. Contrary to this study, in which women predominated other studies ${ }^{(11,19)}$.

In a study about adherence to the treatment of chronic diseases, we consider that socioeconomic factors, such as income, lower education, younger age groups, men and blacks show little adherence to the prescribed therapeutic regimen ${ }^{(20)}$. It is observed that the level of schooling, lower purchasing power, advanced age and long diagnosis time are considered predictors of self-care deficit and low adherence to treatment, due to the lack of understanding of the established therapeutic scheme, corroborated by previous studies ${ }^{(5,8,11,17-19)}$.

In this study, hypertension associated with DM leads to polypharmacy, which is a crucial problem in treatment management. Due to multiple medication use, it is possible that the use of one or more drugs and even insulin is neglected, resulting in a lack of control of recommended glycemic levels, since glucose is sensitive to change in medication use. Another study found a strong association between a greater number of chronic diseases and low adherence. Individuals who used three or more drugs had a higher prevalence of inadequate adherence ${ }^{(20)}$.

Regarding non-pharmacological treatment as physical activity practice and nutritional monitoring, there was no positive result. Few participants performed one or other behavior. A previous study on the self-care practices of Chinese individuals with DM showed that the majority (56\%) did not practice enough exercises and only $6 \%$ had sufficient physical activity for glycemic control ${ }^{(19)}$. Physical exercise and balanced feeding are dynamic strategies and are self-care practices in favor of health and quality of life.

Regarding behavioral beliefs, it is believed that people believe that when they take insulin correctly, they will maintain their health, with control of glycemic levels and will not need to associate other medicines, such as oral antidiabetic drugs (OAD). The positive belief in insulin use lies in the decrease of glycemic levels soon after the application and absence of adverse effects suffered with the use of oral hypoglycemic agents. These beliefs are consistent and favorable to the adherence of the injectable treatment, beneficial and protective effects of the intensive treatment.

A similar study related to the use of OAD among patients with 2DM verified similar beliefs, since the use of OAD helped to remain well, controlled blood glucose and controlled $\mathrm{DM}^{(5)}$. These results suggest that people believe in improving health and disease control by depositing their beliefs exclusively in pharmacological treatment, whether oral or injectable. Insulin therapy is the second pharmacological resource introduced in the therapeutic approach to glycemic control of the person with $2 \mathrm{DM}$, to supply the deficiency of the body in the production of hormones or by the insulin resistance to the standard treatment employed, even if the individual has total adherence to the established oral therapy.

In this sense, it is salutary to strengthen the advantages of the correct use of insulin therapy as strategies of health education with the objective of enhancing knowledge, management for self-care and adherence to therapy instituted concurring to maintain glycemic levels, clinical stability of DM and, therefore, the quality of life of this population. 
Regarding the disadvantages in the use of the prescribed insulin, stands out "pierced pain for insulin application". It is noted that, for most of the interviewees, the pain sensation is negative, which can compromise its correct and regular use. This fact may be related to the lack of knowledge about the correct administration of insulin, fragility or absence in the rotation of the application sites, as well as the use of poor quality needles. Insulin application pain can be minimized with the proper handling of disposable pens and tablets. However, these technological increments may not be accessible to the extracts of the low-income population.

Insulin therapy becomes necessary and essential at some point in the treatment of DM. However, it is difficult to implement and requires special needs related to the preparation and application of insulin ${ }^{(21)}$. Thus, the findings open perspectives for the development of motivational strategies and the confrontation of barriers that hinder self-administration of insulin directed to the patients and families responsible for the application.

With regard to adverse effects, such as hypoglycemia, mild bleeding, purplish spots and application site hardening, these often occur due to the transition from oral to multiple dose injections, the type of insulin used, and the permanence of application at the same place. In such cases, in order to minimize them, frequent returns to health professionals (doctors and nurses) are necessary for dose adjustments and reorientations on administration and change of application sites. Thus, it is reaffirmed the need of the professionals to contemplate in their recommendations the possible adverse events that occur in the first days of the treatment, due to the increase in the quantity and the frequencies of the dose or the alteration of the type of insulin ${ }^{(11)}$.

With reference to the place of application always in the belly, it is presumed a certain difficulty of manual dexterity, inadequate technique and ignorance of the indicated anatomical sites for application. It is known that cognitive and functional limitations impair the autonomy of users for self-application. Therefore, the importance of the implementation of educational health actions directed at self-care is highlighted, as it targets the insulin administration sites and techniques, contributing with the positive impact on its correct use, reducing possible complications ${ }^{(22)}$.

Considering the complex use of insulin, participants are disbelieved because of their adverse effects. This may weaken the maintenance of glycemic and metabolic control, causing an unfavorable impact on the clinical management of the disease. This affirmation can be justified by the high glycemic levels and glycated hemoglobin present in this sample, in addition to the chronic complications identified. Research on the factors associated with glycemic control found a greater probability of inadequate glycemic control in people with a longer diagnosis of the disease, with fewer referrals to endocrinologists and with complex pharmacological therapy ${ }^{(9)}$. Thus, the need to revert negative beliefs against the disadvantages of established therapy is reinforced. It is recommended to use persuasive communications as an interventional means to strengthen positive beliefs and revert negatives by considering social and cultural behaviors constructed throughout life and difficult to modify for the adult population, in order to strengthen abilities and potentialities for the correct use of prescribed therapy.

With regard to normative beliefs, it is noted by the findings that family members are those who support/encourage the correct use of insulin. It is believed that the participation of a social network of positive support is fundamental for the successful adherence to the self-care measures of the disease. Corroborating with the study, spouses, children and family were also cited as positive referents in the motivation for adherence to OAD treatment ${ }^{(11)}$. Family members, relatives and friends should be involved and may positively influence adherence to the established therapeutic regimen.

It should be noted that health professionals (doctors, nurses, nutritionists) were not mentioned as positive or active referents in insulin use, only the medical professional was mentioned, but at very low frequency, evidencing the fragility of the link between team and patients. Corroborating, studies evidenced that health professionals did not emerge as influential in adherence therapeutics for DM control ${ }^{(5,11)}$.

The clinical assistance provided is focused on the written communication approach, making it difficult for the patient to understand the medication prescribed, perhaps only by updating the medical prescription. The low integration of health professionals with patients is indicated as one of the factors that negatively influences the knowledge and acceptance of the disease and, consequently, inadequate adherence to the treatment. Care management must be co-responsibility between health team and users, with accessibility to a sensitive and motivational dialogue ${ }^{(9)}$.

In this sense, the role of the family nucleus as a motivational agent for insulin use is reinforced. Thus, rethinking the care offered to this population, especially by health professionals, is fundamental to strengthen the professional/patient link with the perspective of glycemic control, with positive effects on healthrelated quality of life. It is suggested that educational activities with multidisciplinary integration can be instituted.

Regarding the control beliefs, it is identified that the routine stability of taking the injectable drug, the easy application of insulin and the need to only take a daily dose, as well as the access to treatment and inputs by the national drug policy instituted are contributing factors to insulin use therapy, as prescribed. For these reasons, it is understood the need to reinforce the facilities and resources available for the correct use of insulin in the daily routine, given the flexibility for self-management of the therapeutic regimen. Such beliefs demonstrate that insulin use depends on the distribution of inputs, such as the right amount, syringes, appropriate needles, cotton and alcohol. These are external contributory elements to the ability to execute interest behavior. However, there is a need to foster knowledge about the treatment in order to enhance skills and techniques in the correct use of insulin therapy.

It was also observed that the difficulty in the application of insulin (understanding the prescription, identifying the dose in the syringe, handling at the application site and insecurity of self-application), resistance to insulin, insulin purchase, and pain triggered by application were beliefs elicited as barriers to behavioral performance. These data refer us to reflections about the understanding of the guidelines provided by health professionals to the diabetic patient. Thus, it becomes imperative to clarify the advantages of the therapeutic process for glycemic control in order to avoid clinical emergencies and undesirable hospitalizations, high costs to the health system and negative adverse effects. Additionally, studies show the level of schooling, advanced age, absence or diminution of visual acuity and functional loss as factors that hinder the application of insulin ${ }^{(23-26)}$. 
A prospective and developed cohort study in the United Arab Emirates, which used sessions of educational interventions to promote adherence to medication, showed satisfactory results in patients who did not adhere to the use of medications ${ }^{(24)}$. Another exploratory study using short message service focused on positive results related to insulin administration in young adults with 1DM found that after two weeks of intervention, participants increased adherence to insulin therapy ${ }^{(13)}$. Thus, care technologies can be tested to increase knowledge, skills, strengthening the coping ability to difficulties the daily and continuous administration of the drug. It is important to include family, friends and neighbors in the collaborative network or health service in the support process in adhesion.

Resistance in accepting insulin often runs counter to the sense of responsibility for the unsatisfactory response of oral therapy and the need for inclusion of injectable treatment. In a study with insulin-users, the non-adherent group justified symptoms of malaise and tremors, out-of-date prescriptions, forgetfulness and lack of treatment as they improved, triggering uncontrolled levels of blood glucose and glycated hemoglobin ${ }^{(25)}$.

Uncontrolled DM is also affected by the need for insulin acquisition, when the dispatch is insufficient within a month or by switching from conventional insulin to analogues. This practice is incorporated by medical professionals because they believe in the best action of glycemic control, although there is no evidence of superiority between one or the other ${ }^{(26)}$.

Although the Brazilian Unified Health System (SUS - Sistema Único de Saúde) has a distribution network of essential drugs for the control of chronic non-transmissible diseases including DM, the population affected by this vulnerability suffers from the lack of these drugs of continuous use ${ }^{(21)}$. Certain drugs, like analog insulins, are not included in the free distribution list by the SUS, except by judicial means. The delay in the responses of these processes leaves the patients uncovered and in the obligation to acquire with own resources.

Research on the availability of medications in Basic Health Units reveals that the variety of medicines is restricted, especially in small towns, being found only in $65.9 \%$ of the units ${ }^{(27)}$.

Insulin purchase and pierce pain stand out as barriers to noncompliance with correct and continuous use of insulin. Considering the low purchasing power and fear of pierce pain, many tend to suppress some schedules or days of use of the insulin, to save and to escape the suffering of the pain. In a study with participants who did not adhere to insulin use, he identified oblivion, expired prescription and waiting for the next consultation to withdraw the medication, as justifications for non-adherence ${ }^{(25)}$. There is a need for awareness of the severity of the decompensated disease followed by acute and chronic complications due to non-compliance with the treatment regimen due to interruption or abandonment of treatment.

A study conducted in Tanzania has identified a lack of resources for the free supply of medicines as the most prevalent reason for low adherence. Most patients waited until the next appointment, with an interval of more than one month to get the medication ${ }^{(17)}$. It is noticed that the lack of resources, by the population and health services, interferes in the continuity of the treatment. This is due to the lack of glycemic control and, consequently, complications that could be avoided or minimized by correct and regular use of medication. In this context, it is the role of the public administration to recognize the extension of the problems related to DM with low adherence to treatment, supporting the implementation of infrastructure, with goals related to prevention, promotion of treatment and services of reference to the needy and vulnerable population ${ }^{(27-28)}$.

\section{Study limitations}

The scarce number of publications with the theory related to adherence to injectable therapy in the control of 2DM. Although TPB is already a suitable theoretical-methodological model for studies of health behavior, its application is still scarce in Nursing, considering chronic diseases, especially in the Brazilian context. It is recommended to expand the studies involving the theme to elucidate and diffuse the variables that prevent or facilitate the behavior of insulin use considering the disease a worldwide epidemic.

\section{Contributions to Nursing and Public Health}

The results of this study with the achievement of the objective are important for the practice of nursing, in order to understand and intervene in the negative beliefs and difficulties identified. It is pointed out tools that support strategies of educational interventions, in the sense of strengthening positive variables and reversing those of negative senses to the promotion of actions that protect health. For the practice of Nursing and Health, this evaluation modality has its benefits, as it helps the professionals to identify in the population with chronic disease, the patients with propensity to have low adhesion of treatment.

It is important to emphasize that this is a pioneering research in Brazil, since in the national setting there is no similar study aimed at insulin use in light of TPB.

\section{CONCLUSIONS}

The results of this study allowed to identify the behavioral, normative and control beliefs about insulin use therapy of people with 2DM.TPB proved to be a suitable theoretical-methodological model to analyze beliefs to understand the phenomenon investigated. The advantages of maintaining controlled DM, being safe and controlling glycemic control. As normative referents, the family members who positively support insulin treatment, with a greater presence for the children, stand out as normative referents. Among the easiness for adherence are the application of insulin, free receipt, routine and once-daily use. As barriers to non-use, they are difficult to apply, resistance to accept, insulin purchase and pierce pain.

The identified beliefs will support the construction of psychometric scale to measure the determinants of insulin use in people with 2DM and structuring of educational interventions to reinforce adherence to treatment with adequate glycemic control. Therefore, it is opportune to highlight the relevance of this modality of theoretical study with possibility, offering benefits for the strengthening of behavior through health education to people with difficulties in adherence to treatment and self-care. 


\section{REFERENCES}

1. Tambascia M, Minicucci WJ, Pimazoni Netto A, organizadores. Diabetes na prática clínica: módulo 1 [ebook]. Rio de Janeiro: Sociedade Brasileira de Diabetes; 2014.

2. Stevanim, FL. Diabetes [Internet] Rio de Janeiro: Fiocruz; 2015 [cited 2018 Aug 26]. Available from: https://portal.fiocruz.br/diabetes

3. International Diabetes Federation (IDF). Diabetes Atlas [Internet]. Brussels: IDF; 2017. [cited 2019 Jan 02]. Available from: https://www.idf. org/e-library/epidemiology-research/diabetes-atlas/13-diabetes-atlas-seventh-edition.html

4. Sociedade Brasileira de Diabetes (SBD). Diretrizes 2014-2015 [Internet]. São Paulo: AC Farmacêutica; 2015. [cited 2018 Oct 25]. Available from: https://edisciplinas.usp.br/pluginfile.php/381922/mod_resource/content/1/diretrizes-sbd-2015\%20\%281\%29.pdf

5. Wu P, Liu N. Association between patients' beliefs and oral antidiabetic medication adherence in a Chinese type 2 diabetic population. Patient Prefer Adherence 2016:10 1161-7. doi: 10.2147/PPA.S105600

6. Melzer AC, Uman J, Au DH. Adherence to oral medications for hypertension and diabetes in veterans with comorbid airflow limitation. Ann Am Thorac Soc. 2015;6(12):831-7. doi: 10.1513/AnnalsATS.201501-0010C

7. Pihau-Tulo ST, Parsons RW, Hughes JD. An evaluation of patients' adherence with hypoglycemic medications among Papua new Guineans with type 2 diabetes: influencing factors. Patient Prefer Adherence. 2014;8:1229-37. doi: 10.2147/PPA.S66655

8. Januzzi FF, Rodrigues RCM, Cornélio ME, São-João TM, Gallani MCBJ. Beliefs related to adherence to oral antidiabetic treatment according to the Theory of Planned Behavior. Rev Latino-Am Enfermagem. 2014;22(4):529-37. doi: 10.1590/0104-1169.3578.2448

9. Lima RF, Fontbonne A, Carvalho EMF, Montarroyos UR, Barreto MNSC, Cesse EAP. Factors associated with glycemic control in people with diabetes at the Family Health Strategy in Pernambuco. Rev Esc Enferm USP. 2016;50(6):937-44. doi: 10.1590/S0080-623420160000700009

10. McKinney O, Modeste NN, Lee JW, Gleason PC. Predicting Malawian women's intention to adhere to antiretroviral therapy. J Public Health Res. 2015;4(2):533. doi: 10.4081/jphr.2015.533

11. Guénette L, Lauzier S, Guillaumie L, Giguère G, Grégoire JP, Moisan J. Patients' beliefs about adherence to oral antidiabetic treatment: a qualitative study. Patient Prefer Adherence 2015;9:413-20. doi: 10.2147/PPA.S78628

12. Ajzen I. The Theory of Planned Behavior. Organizational behavior and human decision processes. 1991;50(2):179-211. doi: 10.1016/0749-5978(91)90020-T

13. Louch G, Dalkin S, Bodansky J, Conner M. An exploratory randomised controlled trial using short messaging service to facilitate insulin administration in young adults with type 1 diabetes. Psychol Health Med. 2013;18(2):166-74. doi: 10.1080/13548506.2012.689841

14. Ajzen I. Consumer attitudes and behavior. 2008. In.: Haugtvedt CP, Herr PM, Cardes FR, editors. Handbook of Consumer Psychology, Publisher: New York: Lawrence Erlbaum Associate; 2008. p. 525-48.

15. Ajzen I, Fishbein M. Understanding attitudes and predicting social behavior. Englewood Clifs: Prentice Hall; 1980.

16. Francis C, Francis AJJ, Eccles MP, Johnston M, Walker A, Grimshaw J, et al. Constructing questionnaires based on the theory of planned behaviour: A manual for health services researchers [monograph] [Internet]. Newcastle upon TyneCentre for Health Services Research, University of Newcastle upon Tyne; 2004 [cited 2018 Aug 11]. Avaiable from: http://openaccess.city.ac.uk/id/eprint/1735

17. Rwegerera GM. Adherence to anti-diabetic drugs among patients with Type 2 diabetes mellitus at Muhimbili National Hospital, Dar es Salaam, Tanzania - A cross-sectional study. Pan Afr Med J. 2014;17:252. doi: 10.11604/pamj.2014.17.252.2972

18. Santos CMJ, Faro A. Autoeficácia, lócus de controle e adesão ao tratamento em pacientes com diabetes tipo 2 [Internet]. Rev SBPH. 2018 [cited 2018 Nov 15]21;1:74-91. Available form: http://pepsic.bvsalud.org/pdf/rsbph/v21n1/v21n1a05.pdf

19. Zhou Y, Liao L, Sun M, He G. Self-care practices of Chinese individuals with diabetes. Exp Ther Med. 2013;5(4):1137-42. doi: 10.3892/ etm.2013.945

20. Tavares NUL, Bertoldi AD, Mengue SS, Arrais PSD, Luiza VL, Oliveira MA, et al. Factors associated with low adherence to medicine treatment for chronic diseases in Brazil. Rev Saúde Pública. 2016;50 (Supl. 2):10s. doi: 10.1590/s1518-8787.2016050006150

21. Pires AC. Principais estudos clínicos comparativos entre biossimilares e produtos de referência [Internet]. In.: Sociedade Brasileira de Diabetes (SBD). Posicionamento oficial SBD n 01/2018. Insulinas biossimilares no tratamento do diabetes. São Paulo: SBD; 2018 [cited 2018 Nov 15]. Available from: https://www.diabetes.org.br/publico/images/2018/posicionamento-oficial-sbd-01-2018-biossimilares-versao-finaloficial-04-mai-2018.pdf

22. Moreira TR, Toledo LV, Colodette RM, Mendonça ET, Amaro MOF, Ayres LFA, et al. Factors related to the self-application of insulin in subjects with diabetes mellitus. Rev Gaúcha Enferm. 2018;39:e2017-0066. doi: 10.1590/1983-1447.2018.2017-0066

23. Figueira ALG, Gomes-Villas Boas LC, Coelho ACM, Foss-Freitas MC, Pace AE. Educational interventions for knowledge on the disease, treatment adherence and control of diabetes mellitus. Rev Latino-Am Enfermagem. 2017;25:e2863. doi: 10.1590/1518-8345.1648.2863

24. Shehab A, Elnour AA, Swaidi SA, Bhagavathul AS, Hamad F, Shehab O, et al. Evaluation and implementation of behavioral and educational tools that improves the patients' intentional and unintentional non-adherence to cardiovascular medications in family medicine clinics. Saudi pharm J. 2015;24(2):182-8. doi: 10.1016/j.jsps.2015.02.022 
25. Trevizan H, Bueno D, Koppitke L. Avaliação da adesão ao tratamento de pacientes usuários de insulina em uma unidade de atenção primária à saúde. Rev APS. 2016 [cited 2018 Dec 28];19(3):384-95. Available form: https://aps.ufjf.emnuvens.com.br/aps/article/view/2627/1015

26. Mega TP. Diabetes melito: ainda a questão da insulina? [Internet]. In.: Organização Pan-Americana da Saúde (OPAS). Uso Racional de Medicamentos: fundamentação em condutas terapêuticas e nos macroprocessos da Assistência Farmacêutica. Brasília: OPAS; 2016 [cited 2018 Dec 22];1(19):1-8. Available form: https://www.paho.org/bra/index.php?option=com_docman\&view=download\&alias=1547-diabetesmelito-ainda-a-questao-da-insulina-7\&category_slug=serie-uso-racional-medicamentos-284\&ltemid=965

27. Mendes LV, Campos MR, Chaves GV, Silva RM, Freitas PS, Costa KS, et al. Disponibilidade de medicamentos nas unidades básicas de saúde e fatores relacionados: uma abordagem transversal. Saúde Debate. 2014;38:109-23. doi: 10.5935/0103-1104.2014S009

28. Borba AKOT, Marques APO, Ramos VP, Leal MCC, Arruda IKG, Ramos RSPS. Factors associated with elderly diabetic adherence to treatment in primary health care. Ciênc Saúde Colet. 2018;23(3):953-61. doi: 10.1590/1413-81232018233.03722016 